\title{
Metadiscursos morais e as supostas gafes de Dilma ${ }^{1}$
}

\author{
Roberto Leiser Baronas \\ Universidade Federal de São Carlos (UFSCar), São Carlos, São Paulo, Brasil \\ baronas@ufscar.br \\ https://orcid.org/0000-0003-0758-0370
}

DOI: http://dx.doi.org/10.21165/el.v47i3.2056

\begin{abstract}
Resumo
Neste artigo, analisamos discursivamente um conjunto de textos que abordam as possíveis gafes cometidas pela presidente do Brasil, Dilma Rousseff, em seus pronunciamentos, ao longo de seus dois mandatos à frente da presidência do Brasil. Trabalharemos mais especificamente com o livro Dilmês: o idioma da mulher sapiens, de autoria do jornalista Celso Arnaldo de Araujo e publicado em 2015. A escolha desse corpus mais ou menos peculiar tem a ver com o fato de que o livro de Araujo se apresenta como uma compilação das principais gafes cometidas pela presidenta Dilma e que circularam em diferentes dispositivos comunicacionais. Teórico-metodologicamente ancoramos as nossas discussões nos recentes trabalhos de Paveau (2015) sobre a análise da dimensão moral dos discursos. Partimos da hipótese de que as possíveis gafes cometidas pela então presidente do Brasil, para além e aquém de uma questão de gênero, podem ser enquadradas enquanto um "acontecimento discursivo moral" (PAVEAU, 2015).
\end{abstract}

Palavras-chave: discurso; comunicação política; acontecimento discursivo moral.

\section{Moral metadiscurses and the suggested gaffes of Dilma}

\begin{abstract}
In this article, we aim to analyze, based on French discourse analysis, a set of texts that treats the possible gaffes committed by the president of Brazil, Dilma Rousseff, in her pronouncements, during her two government period at the head of the Brazilian presidency. We will work more specifically with the book Dilmês: o idioma da mulher sapiens (in Portuguese) wrote by the journalist Celso Arnaldo de Araujo and published in 2015. The choice of this peculiar corpus has to do with the fact that Araujo's book presents itself as a compilation of the principal gaffes committed by President Dilma and circulated in different communicational devices. For this work, we anchor our reflections based theoretically-methodologically in recent work of MarieAnne Paveau (2015) about the analysis of the moral dimension of discourses. We start from the hypothesis that the possible gaffes committed by the president of Brazil, beyond a gender issue, can be framed as a "moral discursive event" (PAVEAU, 2015).
\end{abstract}

Keywords: discourse; political communication; moral discursive event.

\footnotetext{
${ }^{1}$ Uma versão bastante modificada deste texto foi inicialmente apresentada na mesa redonda "Discurso político e mídia: princípios teórico-metodológicos”, realizada na UFSCar, em 08 de junho de 2017, depois reescrita em coautoria com a minha colega e amiga Júlia Lourenço Costa e publicada na Revista Intersecções da UniAnchieta, edição 23, em agosto de 2017. O artigo pode ser acessado em: $<$ http://www.portal.anchieta.br/revistas-e-livros/interseccoes/pdf/interseccoes-ano-10-numero-2.pdf $>$.
} 


\section{Primeiras palavras}

Uma vista d'olhos na literatura pertinente nos mostra que são raros os trabalhos que se debruçaram sobre a compreensão das gafes no âmbito da política, mesmo sendo um fenômeno recorrente nesse campo. A maioria dos trabalhos ${ }^{2}$ que se debruça sobre essa temática geralmente se resume a listar com acentuadas doses de ironia ou humor as gafes cometidas pelas mais variadas pessoas públicas, incluindo políticos eleitos, candidatos, assessores, entre outros.

No contexto acadêmico francês, no entanto, cumpre destacar o trabalho de Le Bart e Teillet ${ }^{3}$, no qual os autores com base em uma perspectiva discursiva buscam mostrar que as gafes, assim como os lapsos são subgêneros com características linguísticas, temáticas e estilísticas próprias, que constituem um gênero maior, o discurso político. A preocupação dos autores é com a diferenciação genérica desses elementos de linguagem.

No Brasil, merece destaque o trabalho de Mayara Victor Gomes ${ }^{4}$, no qual a autora, a partir de um corpus construído por gafes atribuídas a diferentes presidentes do Brasil (Fernando Henrique Cardoso, Luís Inácio Lula da Silva e Dilma Rousseff), busca compreender com base em Maingueneau (2015), a partir da teoria das frases sem texto, o que transforma um comentário de um ator político qualquer em gafe, isto é, o que faz desse enunciado uma espécie de pandemia discursiva que circula rapidamente por meio das mais diferentes mídias não só nacionais, mas também estrangeiras. A autora busca compreender também até que ponto um comentário que era para circular numa esfera mais restrita (a de um político com os seus assessores, por exemplo) e que, por alguma razão, ganha a esfera pública é o elemento determinante na sua transformação em gafe, se constituindo no que alimenta o debate político durante várias semanas.

Apesar de Le Bart e Teillet e Victor Gomes engendrarem uma importante contribuição para pensar a gafe no âmbito da política de uma mirada discursiva, deslocando-a da simples catalogação ou da discussão do humor por ela provocado, é preciso levar em consideração que as gafes, sobretudo, no campo da política, são discursos sobre discursos, que produzem os mais diferentes tipos de acontecimento, podendo ser de natureza moral. Esse aspecto acontecimental moralizante das gafes não foi pensado de maneira mais detida por nenhum dos autores mencionados.

Nesse sentido, com base no nosso pequeno corpus de estudo, as supostas gafes de Dilma Rousseff, compiladas no livro Dilmês: o idioma da mulher sapiens, é possível asseverar que o acontecimento engendrado pelas gafes é de natureza moral, ou seja, um acontecimento moral produzido por um "conjunto de comentários e reações [disfóricas], em dado grupo ou sociedade, a propósito de um enunciado". (PAVEAU, 2015, p. 96), visto que de alguma maneira esse enunciado fere a(s) norma(s) social(is) da fala.

\footnotetext{
${ }^{2}$ Uma representação metonímica desse tipo de trabalho é o livro Pisando na bola: causos e gafes da política, de João Bosco Vaz, publicado pela Editora Nova Prova, de Porto Alegre em 2005.

${ }^{3}$ LE BART, C.; TEILLET, P. « Erreur, lapsus, gaffes, fautes : le discours politique comme genre », L'analyse de discours. RINGOOT, R.; ROBERT-DEMONTROND, P. (Éd.). Rennes: Editions Apogée, 2004. p. 53-85.

${ }^{4}$ VICTOR GOMES, M. Das gafes às aforizações em política: questões teórico-analíticas. Relatório de iniciação científica, desenvolvido na Universidade Federal de São Carlos, sob os auspícios da FAPESP, Processo número 2013/17191-3.
} 


\section{Sobre o corpus e o seu tratamento discursivo}

O nosso pequeno corpus de estudo é o livro Dilmês: o idioma da mulher sapiens, lançado pelo jornalista Celso Arnaldo Araujo, em 2015. A eleição desse livro como um corpus mais ou menos peculiar se deve ao fato de que ele se apresenta como uma espécie de representação metonímica do acontecimento moral, designado como "dilmês" : um simulacro de idioma criado pelos mais diferentes dispositivos midiáticos para caracterizar disforicamente as falas de Dilma Rousseff em seus pronunciamentos. Com efeito, essa designação "dilmês" nome Dilma, mais o sufixo -ês, extraído da terminação de muitas línguas: portugu-ês; ingl-ês; franc-ês, escoc-ês, irland-ês, etc., traz na própria materialidade linguística o sentido disfórico. Em outros termos, o sufixo -ês ao ser incorporado ao radical dilm-passa a funcionar como uma marca disfórica. Esse termo também dialoga interdiscursivamente com outro simulacro de idioma criado alhures por diferentes dispositivos midiáticos, que é o Lulês, termo que caracteriza negativamente as falas do então presidente do Brasil, Luís Inácio Lula da Silva. Por entendermos que as críticas às supostas gafes da presidenta Dilma Rousseff produzem esse acontecimento discursivo moral, o dilmês, buscamos acolhida teórico-metodológica nos trabalhos de Marie-Anne Paveau (2015) acerca da reflexão sobre a dimensão moral dos enunciados. Não é nosso desejo fazer neste material uma análise exaustiva. Consideraremos apenas alguns aspectos, também com a finalidade de corroborar as teses de Marie-Anne Paveau sobre a necessidade de se compreender numa análise discursiva a dimensão moral dos enunciados.

Em seu livro Linguagem e moral: uma ética das virtudes discursivas, Marie-Anne Paveau busca integrar o parâmetro ético na linguística. Parâmetro que, embora constitutivo da linguagem, por questões de objetividade científica, foi completamente deixado à deriva tanto no estruturalismo quanto no gerativismo. Para incorporar tal parâmetro em seu trabalho, a autora discute, por um lado, a ética do discurso acadêmico: os problemas de deformação das teorias, roubo de ideias e requalificação ou atribuição

\footnotetext{
${ }^{5}$ Uma procura no site de buscas Google apresenta 26.400 ocorrências para o termo Dilmês. Esse número significativo de ocorrências mostra a pertinência dessa discussão para os estudos dos discursos que se debruçam na compreensão das relações entre discurso e moral.

${ }^{6}$ A revista francesa de atualidades $L$ 'OBS publicou em dezembro de 2009 o artigo "Dix ans de gaffes, bévues et boulettes politiques: Raffarinades, ségolènades, bushismes, sarkonneries... le best of des bourdes de nos politiques, français ou étrangers, de ce début de siècle". Esse artigo nos mostra que também no contexto francês há toda uma prática jornalística de identificação das gafes com os seus autores, isto é, a partir dos nomes dos políticos constrói-se uma marca de identificação de suas gafes: Raffaran = raffaranidades; Ségolène = ségolènades; Sarkozy = sarkonneries; Busch = bushismes, etc. No entanto, no caso brasileiro, sobretudo em relação à Dilma e a Lula a marca de identificação a suas gafes - Dilmês e Lulês - tem a ver não somente com o uso inadequado de uma palavra ou termo, como no contexto francês, mas com a criação de um idioma próprio. Nesse caso, me parece que o efeito disfórico é potencializado. $\mathrm{O}$ artigo em questão $\quad$ pode $\quad$ ser acessado $<\underline{\text { http://tempsreel.nouvelobs.com/politique/20091216.OBS0854/dix-ans-de-gaffes-bevues-et-boulettes- }}$ politiques.html $>$.
} 
errônea de $\operatorname{conceitos}^{7}$; e, por outro, a ética da fala ${ }^{8}$ : um dispositivo moral relativamente à língua e aos discursos, cujas análises, embasadas numa espécie de linguística popular, são abundantes em juízos axiológicos, que identificam os enunciados como bons ou ruins. Para dar conta da dimensão moral dos enunciados, Paveau (2015) propõe uma filosofia do discurso ou uma linguística simétrica, que diferentemente das escolas estruturalistas e formalistas, bem como de domínios como a sociolinguística, a pragmática ou a retórica, não propõe uma separação entre o que é da ordem do sistêmico ou da competência dos falantes e o que é da ordem do contexto, mas sim uma integração dessas ordens, a partir da análise da dimensão moral dos discursos.

Cumpre destacar que não trataremos aqui das questões éticas relacionadas ao discurso acadêmico, mas do que Paveau (2015) designa como "a ética da fala", ou seja, todo um conjunto de juízos axiológicos que é feito pelos mais variados atores sociais, incluindo o autor do livro que é nosso objeto de análise, acerca do suposto mau uso que a presidenta Dilma Rousseff faz da língua portuguesa e da retórica, em seus pronunciamentos. Essas críticas são designadas por esses atores sociais como gafes. O verbete gafe está registrado no Dicionário Eletrônico Houaiss de Língua Portuguesa como "ato e/ou palavra impensada, indiscreta, desastrada; indiscrição involuntária". Todavia, discursivamente, entendemos que as gafes possuem uma função argumentativa - descaracterizar o discurso do outro - e um funcionamento axiológico - apresentar um juízo de valor acerca do discurso de alguém.

O livro Dilmês: o idioma da mulher sapiens, de autoria de Celso Arnaldo de Araujo foi publicado em 2015 pela Editora Record do Rio de Janeiro. Esse livro conta com um prefácio do professor aposentado do Departamento de Letras da Universidade Federal de São Carlos - UFSCar, Prof. Dr. Deonísio da Silva, intitulado "O português de Dilma" e está organizado em forma de quinze "crônicas" que discutem as gafes supostamente cometidas pela presidenta em suas intervenções: pronunciamentos oficiais, entrevistas. Essas "crônicas" estão organizadas a partir de fragmentos dos discursos da presidenta e juízos axiológicos do autor acerca desses fragmentos. Não há nessas “crônicas' nenhum tipo de análise linguística dos fragmentos de discurso da presidente

\footnotetext{
${ }^{7}$ Um bom exemplo do que Paveau entende como ética do discurso acadêmico, especialmente no que tange à atribuição errônea de conceitos, pode ser encontrado na apresentação da tradução do livro Materialidades Discursivas. Esse livro, resultado de um colóquio realizado em abril de 1980, na Universidade Paris X, Nanterre, na França, traz um conjunto de textos de linguistas, historiadores, psicanalistas e discursivistas que buscam discutir, entre outras questões, o que é lidar com a materialidade discursiva. Nessa apresentação, a organizadora da tradução Eni Orlandi critica a aplicação epistemologicamente problemática que tem sido feita por muitos discursivistas brasileiros no tocante ao conceito de materialidade discursiva. "A noção de materialidade discursiva é uma dessas noções que têm tido seu uso banalizado [...]. Na maior parte das vezes, chamam de materialidade - por exemplo: 'a materialidade que vou analisar são textos encontrados no jornal x' - o que já está categorizado nas disciplinas de linguagem, em geral, como 'corpus', em algumas como 'objeto de análise'. Mas certamente não cabe chamar isso de 'materialidade"”.

${ }^{8}$ Um exemplo lapidar do que Paveau entende por ética da fala pode ser discutido a partir da declaração do então diretor de futebol do Internacional de Porto Alegre, Fernando Carvalho, acerca do adiamento da última rodada do campeonato brasileiro de 2016, por ocasião da queda da aviação que levava a delegação da Chapecoense para a Colômbia. Disse Carvalho: "Além do sentimento, além da consternação que nossos jogadores estão tomados, que a maioria deles se relacionava com os atletas. Hoje deu para ver na reunião que nós fizemos para dispensar do treinamento. Retomaremos amanhã. Temos nossa tragédia particular, que é fugir do rebaixamento...". Essa fala circulou nas redes sociais e provocou a ira dos torcedores brasileiros. A repercussão pelo uso indevido da palavra tragédia pelo dirigente colorado foi tamanha que Carvalho teve de vir a público se retratar: "Usei um termo equivocado. Usei indevidamente a palavra tragédia. Não é tragédia. O que aconteceu com a Chapecoense foi uma tragédia que não tem volta. No Inter, mesmo que a gente não consiga reverter, a vida vai seguir...”.
} 
Dilma destacados pelo autor, isto é, o autor não mobiliza nenhum dos domínios da linguística para fazer as suas análises. O que há são análises embasadas numa linguística popular ${ }^{9}$, que enquadra os enunciados ou como bons ou ruins.

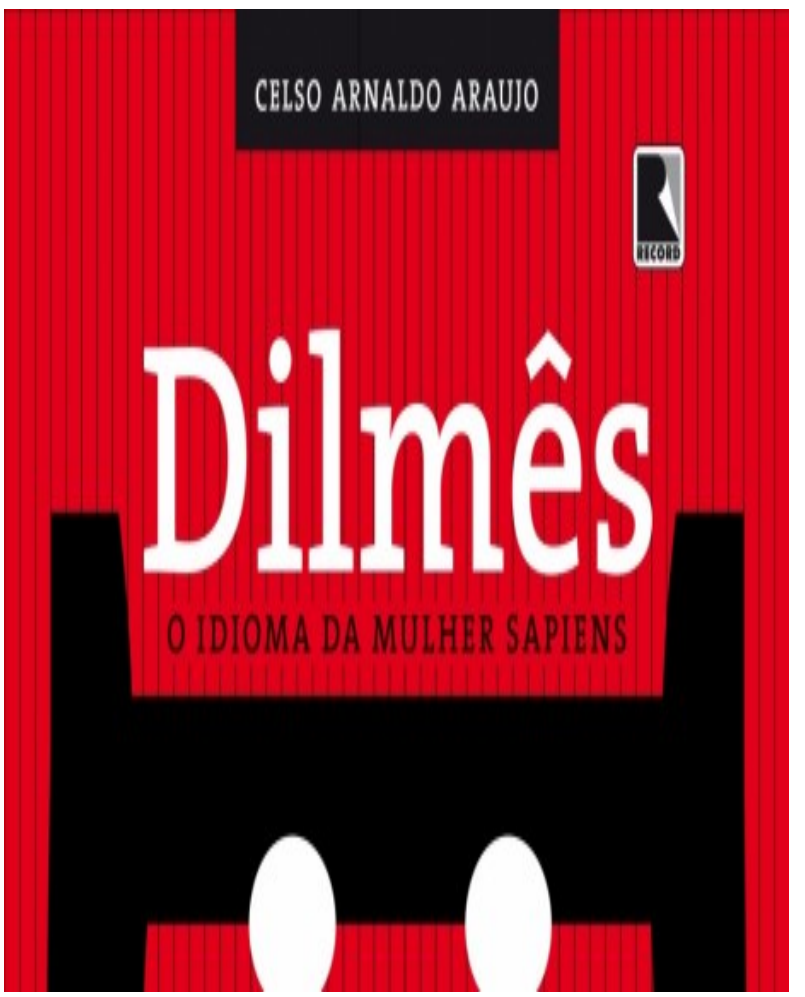

Este livro de Celso Arnaldo de Araujo pode ser considerado uma espécie de representação metonímica do acontecimento discursivo moral, construído pelos mais diferentes dispositivos midiáticos, em relação às falas da presidenta, o "dilmês". O próprio título com destaque para o termo "Dilmês" e o desenho de uma espécie de caricatura do rosto da presidenta $^{1}$, reforçam a construção desse acontecimento discursivo moral. Conforme enunciado, o livro do jornalista busca se apresentar como uma espécie de compêndio que visa condensar em um único dispositivo as principais gafes de Dilma.

Figura 1. Capa do livro "Dilmês: o idioma da mulher sapiens" - de Celso Arnaldo de Araujo

Vejamos a seguir um fragmento retirado do capítulo 09 "Dilmês: um serial killer das letras alheias" do livro de Celso Arnaldo de Araujo:

Naquele 11 de junho de 2010, na celebração da aliança com o PMDB, que resultou na escolha de Michel Temer como seu vice, Dilma fez uma patética "homenagem" a históricos peemedebistas. Na hora de falar de Ulysses Guimarães, atribui-lhe a expressão "Navegar é preciso". Que aliás, segundo ela, era parte de um poema. Ulysses Guimarães, o poeta da abertura: 'Esse verso de Ulysses mostrava que, sobretudo, mesmo quando a esperança é pequena, a coragem das pessoas tem que levá-las a andar'. Verso? Ulysses? Mostrava? Levá-las a andar? Eis numa única frase, uma amostra exemplar de que a desarticulação de Dilma pode alcançar mais de vinte séculos, cobrir dois hemisférios, a história, a literatura, a política e vários outros segmentos do conhecimento humano. (ARAUJO, 2015, p. 106).

O próprio título do capítulo - "Dilmês: um serial killer das letras alheias" - se apresenta como um juízo axiológico em relação às falas de Dilma. A alusão irônica à expressão inglesa serial killer, que designa o criminoso de perfil psicopatológico que comete assassinatos em série, aliada ao complemento das letras alheias, identifica a locutora com o criminoso: se o segundo mata pessoas em série, a primeira também em

\footnotetext{
${ }^{9}$ A expressão linguística popular é uma tradução livre da expressão inglesa folks linguistics e designa as regulações linguísticas feitas por atores socais não especialistas em ciências da linguagem a partir de morais linguageiras da fala.
} 
série, por pura ignorância, assassina as obras de grandes escritores universais. Com efeito, o autor procura evidenciar que as falas da presidenta não são virtuosas, no sentido que Marie-Anne Paveau (2015, p. 214) atribui a este conceito: "o discurso virtuoso é o discurso ajustado aos valores vigentes na realidade complexa e instável e de seus ambientes". Em outros termos, o autor ao comentar as falas de Dilma, avaliando-as como equivalente às práticas de um serial killer, busca evidenciar que essas falas estão desajustadas quanto às relações entre os agentes (no que tange, entre outras coisas, ao valor da inteligência e da sagacidade dos governantes - "Verso? Ulysses? Mostrava? Levá-las a andar? Eis numa única frase, uma amostra exemplar de que a desarticulação de Dilma pode alcançar mais de vinte séculos, cobrir dois hemisférios, a história, a literatura, a política e vários outros segmentos do conhecimento humano". - assim como quanto à memória discursiva em torno dos temas do domínio da literatura e da história.

Para o autor, essas falas de Dilma estão desajustadas também na realidade do mundo, visto que, no imaginário da grande maioria da população, as intervenções esperadas de um presidente da república devem ser as de um estadista que domina os mais variados temas, dentre eles, a literatura. Saber, por exemplo, que Ulysses Guimarães não foi autor da expressão "Navegar é preciso" e sim Fernando Pessoa e também que a interpretação desse dizer - "Esse verso de Ulysses mostrava que, sobretudo, mesmo quando a esperança é pequena, a coragem das pessoas tem que levá-las a andar" - passa pela questão da precisão, isto é, do rigor, da perfeição na execução de um trabalho, e não da necessidade de se fazer algo. Ademais, o autor ao emitir o juízo de valor em relação ao equívoco da presidenta, atribuindo a Ulysses Guimarães uma expressão do poeta português Fernando Pessoa, omite a informação de que o próprio Ulysses em diversas situações públicas, quando enfrentava a ditadura militar nos anos setenta do século passado, empregou o dizer do poeta lusitano com o mesmo sentido atribuído por Dilma.

No conjunto de usuários de uma língua, tomada nos contextos culturais, históricos e sociais, realmente existem critérios para a produção discursiva. Não se trata somente de critérios de gramaticalidade ou agramaticalidade das sentenças como pensava Noam Chomsky em seu livro Syntatic Structures (1957) e nem só de princípios de controle e rarefação dos discursos, como pensava Foucault (1971), em seu livro-programa $A$ ordem do discurso, mas é preciso levar em consideração que as sociedades possuem codificações éticas das práticas linguageiras, que distinguem os bons e os maus discursos. Falar bem ou mal dos discursos é uma prática onipresente em todas as sociedades. Em outros termos, na nossa sociedade a produção e a circulação de discursos também é determinada por critérios éticos. São esses critérios que vão designar um discurso como virtuoso ou não. Assim, no entendimento de Paveau (2015, p. 132).

As éticas discursivas baseiam-se em deontologias, ou seja, em sistemas de normas que regulam o comportamento dos indivíduos de maneira externa, na forma de sistemas de direitos e deveres. Isso ocorre em especial com os sistemas de penalização da fala que se desenvolvem atualmente nas sociedades ocidentais com a forma de leis que condenam afirmações racistas, sexistas, contestações de genocídio ou de crime contra a humanidade. [...]. As normas regulamentam as práticas linguageiras a partir de fora, em virtude de princípios postos acima da produção verbal.

Ao tecer o seu texto com as falas de Dilma, diferenciando-as por meio do uso de aspas e produzindo comentários axiológicos acerca dessas falas, mostrando que elas estão completamente desajustadas aos agentes, à memória discursiva e ao mundo, o autor busca evidenciar que o discurso de Dilma não é virtuoso, isto é, que esse discurso fere as 
codificações éticas que sustentam os bons discursos e que portanto esse discurso deve ser penalizado. Talvez não com o mesmo rigor de penalização, que seria aplicado a um discurso considerado racista, por exemplo. Nesse sentido, como não existe na legislação uma sanção penal para as gafes, o descrédito linguístico do locutor ${ }^{10}$ dessas produções linguageiras é o objetivo visado.

Tomemos agora como objeto de análise um excerto do capítulo 10 do livro de Araujo, intitulado "Papéis secretos do governo Dilma: os únicos escritos conhecidos em dilmês":

No caso de Dilma, qualquer jornalista com um mínimo de espírito crítico se sentiria impelido a revisar, limpar, reordenar cada frase, cada sentença, cada período daquelas falas chacoalhadas e embaralhadas limando a profusão de lapsos, redundâncias, anacolutos, barbarismos, vulgarismos, solecismos, obscuridades, ambiguidades, queismos, cacoépias. Enfim um tratado prático, sem ensaio e sem roteiro do que não se deve fazer com a língua. Mas com os discursos e entrevistas de Dilma, isso nunca ocorre quando a transcrição chega - quase sempre no mesmo dia do evento - às páginas do Portal do Planalto. As únicas correções são em relação aos vulgarismos - o 'ocê' de Dilma, por exemplo, veste uma roupinha um pouco melhor e se torna você. O mesmo ocorre com todos os verbos no infinitivo - dos quais a mineirice extemporânea surrupia o erre final, substituindo-o por um circunflexo (fazê) ou um acento agudo (falá). De resto, os funcionários da Secretaria de Comunicação da Presidência parecem ter um respeito pelas deficiências de linguagem da chefe - como se fossem atilados Champollions diante de suas Pedras de Roseta. De duas uma: ou não tem espírito crítico ou Dilma, através de algum acólito na Secretaria, impôs a absoluta fidelidade ao Dilmês". (ARAUJO, 2015, p. 120-121).

Nesse fragmento, o autor descaracteriza e penaliza a fala da presidenta Dilma, bem como critica os seus colegas jornalistas por não terem cumprido bem o seu ofício que seria o "de revisar, limpar, reordenar cada frase, cada sentença, cada período daquelas falas chacoalhadas e embaralhadas limando a profusão de lapsos, redundâncias, anacolutos, barbarismos, vulgarismos, solecismos, obscuridades, ambiguidades, queismos, cacoépias" das falas da presidenta. Esse tipo de penalização e de crítica só se justifica, isto é, encontra guarida no imaginário da grande maioria da população, pois na nossa sociedade existe um conjunto de normas que penalizam as falas consideradas não virtuosas.

Nesse sentido, para Marie-Anne Paveau (2015), as nossas falas são reguladas por três tipos de sistemas normativos: as normas religiosas; as normas jurídicas e as normas sociais e sociopolíticas. No caso do primeiro sistema, são punidas as blasfêmias e as mentiras; no caso do segundo, são punidas as manifestações que ferem os direitos humanos; a lei de imprensa e os discursos que atentam contra a ordem pública e à defesa

\footnotetext{
${ }^{10}$ Um exemplo interessante acerca desse descrédito linguístico do locutor visado pelo autor do livro em questão pode ser observado na resenha de apresentação desse livro de Araujo, postada no site do Google Books: "A sátira política do saara cerebral de Dilma Rousseff. Ao esmiuçar os mais estapafúrdios conceitos e raciocínios já formulados por uma figura pública brasileira, esta sátira política honra a melhor tradição do gênero com uma viagem ao centro do saara cerebral de Dilma Rousseff. Já em meados de 2009, no exato instante em que a funcionária pública mineira de origem búlgara começou a se apresentar aos brasileiros como presidenciável, era possível notar que havia algo de errado naquele discurso no qual palavras eram despejadas a esmo, sem dar liga a uma única ideia à altura do cargo que postulava. A partir dos discursos presidenciais transcritos na íntegra pelo Portal do Planalto, Celso Arnaldo Araujo, pioneiro na análise sintática e política da língua falada pela presidente da República, destrincha e documenta os verdadeiros espetáculos de comédia bufa protagonizados pela dramática inaptidão da oratória de Dilma".
} 
nacional e, no caso do último sistema, são punidos os discursos politicamente incorretos e os de violência verbal. Cada um desses sistemas estabelece um tipo de punição específica para o delito verbal cometido. Por exemplo, em 1994, no dia da Padroeira do Brasil, o Evangélico Sérgio Von Helde, então bispo da Igreja Universal do Reino de Deus, chutou em um programa evangélico da TV Record a imagem de Nossa Senhora Aparecida. As imagens se espalharam rapidamente por diversos dispositivos. Por conta de seu ato, Von Helde foi execrado publicamente e demitido da sua função de Bispo. Em outro exemplo, a punição foi distinta para a ação que o Ministério Público Federal de Minas Gerais impetrou contra as Editoras que publicam o Dicionário Houaiss de Língua Portuguesa, por considerar que este dicionário em relação ao verbete cigano, ao registrar sentidos como "aquele que trapaceia; velhaco, burlador", agredia de maneira injustificável o patrimônio moral da nação cigana. As editoras foram obrigadas, sob pena de pagarem uma multa de $\mathrm{R} \$ 200.000,00$, a retirar os sentidos pejorativos atribuídos à palavra "cigano".

Os exemplos arrolados nos mostram que em nossa sociedade funcionam mecanismos de penalização das falas. Esses mecanismos são sustentados pelos mais diversos dispositivos morais. No caso das normas religiosas, temos as bíblias, os catecismos, as missas, os cultos, as orações, os mandamentos, as reuniões, entre outros. No caso das normas jurídicas, temos a declaração universal dos direitos humanos, a lei de imprensa, os códigos penais, entre outros. E, no caso das normas sociais, temos os manuais de polidez; do politicamente correto, de etiqueta, de bons modos, entre outros. Todos esses dispositivos sustentam os metadiscursos morais que autorizam o que e quem pode e quando deve dizer na nossa sociedade. Esses mecanismos, por serem construções sócio-históricas, possuem uma certa plasticidade.

No que concerne ao fragmento em questão, as falas de Dilma ferem as normas sociais e sociopolíticas, uma vez que elas, no entendimento de Araujo, são "um tratado prático, sem ensaio e sem roteiro do que não se deve fazer com a língua". Esse tipo de discurso moral sobre a língua se sustenta em diversos instrumentos linguísticos, sobretudo nos compêndios gramaticais, nas cartilhas. Conforme enunciamos, cumpre destacar que as análises do autor acerca das gafes da presidenta não se baseiam em nenhum dos domínios das ciências da linguagem. Trata-se de uma análise realizada a partir de uma linguística popular: um conjunto de morais linguageiras, referendado alhures pelos compêndios gramaticais e sua aplicação no ensino, que circula no imaginário da grande maioria da população, enquadrando os enunciados como bons ou ruins. Uma vista d'olhos na literatura linguística nos mostra que todos os fenômenos arrolados pelo autor como problemas de linguagem da presidenta: "redundâncias, anacolutos, barbarismos, vulgarismos, solecismos, obscuridades, ambiguidades, queísmos, cacoépias" são fenômenos recorrentes no uso cotidiano do português brasileiro, sobretudo na modalidade falada, portanto passíveis de uma descrição, uma explicação e uma interpretação científicas.

\section{Conclusões preliminares}

A nossa preocupação neste artigo não foi a de tomar partido em defesa da presidenta Dilma, mostrando, por exemplo, que ela foi vítima de um golpe midiáticoparlamentar que culminou com a sua destituição do cargo ou que por ser mulher estaria mais suscetível a juízos axiológicos acerca dos usos linguísticos. Entendemos que esses 
juízos linguísticos não passam de forma determinante pela questão de gênero ${ }^{11}$. Embasamos nossa asserção por um lado no fato de que o ex-presidente Lula também foi alvo de duras críticas e zombarias por conta de seus usos linguísticos e, por outro, no tocante ao uso da língua, questões como a dimensão moral do erro, mais do que a questão do gênero é determinante na transformação desse locutor como alvo de críticas, de comentários derrisórios. Em outros termos, Dilma é criticada, punida por seus usos linguísticos, designados como gafes, não pelo fato de ser mulher, mas pelo fato de os agentes sociais entenderem que ela fere os metadiscursos morais que sustentam as nossas práticas linguísticas na sociedade. No caso específico da sociedade brasileira, a dimensão moral do erro linguístico, por conta de todo um processo de limpeza linguística, que busca desde os primórdios de nossa colonização dizimar qualquer manifestação linguística que esteja fora do que é estabelecido como a boa língua, é levada às últimas consequências. Essa dimensão moral do erro linguístico, diferentemente de outros tipos de preconceito, é menos suscetível à plasticidade ${ }^{12}$.

O acontecimento discursivo moral acerca das duras críticas que o MEC recebeu de praticamente todos os setores da sociedade pela aquisição e distribuição do livro Por uma vida melhor ${ }^{13}$ para a Educação de Jovens e Adultos (EJA), em 2011, mostra o quanto a sociedade brasileira dimensiona moralmente de maneira exponencial o erro linguístico.

${ }^{11}$ Um bom lugar para observarmos a presença de comentários axiológicos sobre as mulheres são os provérbios e os ditos populares. Esses pequenos enunciados que dizem muito sobre o papel atribuído à mulher na nossa sociedade dão a circular os mais variados estereótipos sobre as mulheres: são maldosas "Só há duas mulheres boas no mundo: uma que já morreu, outra que ainda não nasceu"; pouco confiáveis - "A graça da mulher é enganosa e a sua virtude confunde-se com o vício"; pouco inteligentes - "A mulher é um animal de cabelo comprido e entendimento curto"; gastadeiras - "A casa é das mulheres e a rua é dos homens"; sexualmente disponíveis - "A mulher não vai além de fêmea"; faladeiras - "Fevereiro tem 28 dias, é o mês que as mulheres falam menos"... No entanto, na nossa sociedade não há nenhum provérbio ou ditado popular que atribua à mulher de forma genérica a autoria por usos linguísticos considerados inadequados. Alguma coisa que poderia ser parafraseada a partir do dito popular "Mulher no volante perigo constante" como "Mulher falando a ignorância se manifestando". Se circulasse, esse suposto provérbio evidenciaria uma relação de causa e efeito, isto é, o fato de a mulher falar implicaria necessariamente a manifestação da ignorância. Há sim pequenas frases que se referem a uma mulher em particular. Falamos, por exemplo, da personagem Magda, interpretada pela atriz Marisa Orth, na série da Rede Globo de Televisão, Sai de Baixo, que ficou conhecida pelo bordão "Cala a boca, Magda!" usado pelo personagem Caco Antibes - Miguel Falabela - todas as vezes que a Magda subvertia um ditado popular como "O universo respira a nosso favor" ou expressões como "conversa franga".

${ }^{12}$ No início de outubro deste ano, a marca Dove deu a circular em seu Facebook um anúncio de sabonete líquido - body wash. Neste anúncio, em um gif, que durava alguns segundos, apareciam três mulheres em sequência: uma negra e duas brancas. Cada uma das modelos tirava a camiseta, transformando-se em outra. A primeira modelo que era negra, ao tirar a camiseta, transforma-se em branca, produzindo um efeito de narrativa: um antes e um depois. Essa transformação da modelo negra em branca foi interpretada por diversos atores sociais como fazendo remissão a uma fórmula racista presente em publicidades de sabonetes e outros cosméticos no passado, em que a pessoa negra "suja" se torna branca ao se limpar. Por ser considerada racista, a publicidade gerou muita polêmica, o que fez com que a empresa removesse esse anúncio poucos dias depois. Todavia, se voltarmos no tempo não mais do que duas dezenas de anos, constataremos que publicidades similares não causaram a mesma polêmica, evidenciando a plasticidade dos critérios que são aplicados pelos atores sociais na penalização dos discursos.

${ }^{13}$ A polêmica sobre o livro foi tão intensa que em 12/05/2011, o MEC veio a público e divulgou a seguinte nota: "Lidar com as diferenças é uma das maiores dificuldades do ser humano. Ao se descobrir a diversidade, em muitas ocasiões, manifesta-se a tensão, a intolerância e, principalmente, o preconceito, que se define como uma postura negativa, sem fundamentos, para com as diferenças manifestadas nas várias dimensões da vida humana. Uma forma de preconceito particularmente sutil é a que se volta contra a identidade linguística do indivíduo e que, mesmo sendo combatido, no Brasil, por estudiosos da sociolinguística continua a ser relevado pela sociedade em geral, inclusive na escola. O reconhecimento da 
É preciso levar em consideração também que o acontecimento discursivo em questão, por conta de todo um histórico na nossa sociedade que dimensiona moralmente de forma exponencial o erro linguístico, se apresenta como mais uma das justificativas para a destituição da presidenta ${ }^{14}$, ocorrida em definitivo em agosto de 2016 , pois busca evidenciar que, como o "dilmês" é um idioma doente, sujo, que carece de "revisão, limpeza, reordenamento de cada frase, de cada sentença, de cada período", o seu criador e principal usuário também estaria doente, sujo, despertando em boa parcela da população brasileira uma espécie de dilmafobia, sustentando, portanto, a necessidade de destituição da presidenta. Com efeito, se do ponto de vista jurídico as pedaladas fiscais foram o principal argumento para a deposição da presidenta, as pedaladas linguísticas ou gafes da presidenta, aliadas às denúncias de corrupção em seu governo, foram o principal argumento para que boa parcela da população brasileira saísse às ruas, referendando a deposição de Dilma ${ }^{15}$.

Para além dos aspectos anteriormente arrolados, as análises do acontecimento discursivo moral "dilmês" e a sua relação com os metadiscursos morais nos mostram a necessidade premente de se começar a trabalhar também, no âmbito do discurso, na esteira do que propõe Marie-Anne Paveau (2015), com a dimensão moral dos enunciados, discutindo, por exemplo, até que ponto aqueles que se apoderam do discurso alheio, como é o caso do livro de Araujo, que dizem disforicamente os pronunciamentos da presidenta Dilma, podem fazer o que bem entendem com esses discursos. Não haveria a necessidade de se perguntar como devemos tratar o discurso alheio de maneira que não seja somente um (mal)tratar?

variação linguística é condição necessária para que os professores compreendam o seu papel de formar cidadãos capazes de usar a língua com flexibilidade, de acordo com as exigências da vida e da sociedade. Isso só pode ser feito mediante a explicitação da realidade na sala de aula. Todas as línguas mudam com o passar do tempo e variam geográfica e socialmente. A respeito da língua, dois fatos devem ser levados em conta: a) não existe nenhuma sociedade na qual todos falem da mesma forma; b) a variedade linguística é o reflexo da variedade social e, como em todas as sociedades existe alguma diferença de status, essas diferenças se refletem na língua. [...]".

${ }^{14} \mathrm{O}$ principal argumento supostamente jurídico para a deposição da presidenta Dilma ficou conhecido como "pedaladas fiscais". Essa expressão, pedaladas fiscais, foi uma designação usada pela grande mídia para descrever uma manobra contábil do governo federal, utilizada também por outros governos anteriores ao de Dilma Rousseff, na qual supostamente o governo da petista objetiva passar a impressão de que arrecadava mais do que gastava. Nesse contexto, o governo não estaria pagando os bancos públicos e privados que financiavam programas sociais como o Bolsa Família. Então, para que os beneficiários não deixassem de receber, os bancos arcavam com as despesas sozinhos, sem receberem a compensação governamental. O Tribunal de Contas da União, em decisão unânime, considerou essa operação um empréstimo dos bancos, não pago pelo governo, ferindo a Lei de Responsabilidade Fiscal. Embora o TCU seja um órgão auxiliar do Legislativo e não tenha poderes para condenar o Chefe do Executivo, ele oferece um parecer prévio, que pode ou não ser acatado pelo Congresso Nacional, abrindo até mesmo a possibilidade de um processo de impedimento da Presidente da República. Fonte: Wikipedia.

${ }^{15}$ Essa relação entre pedaladas fiscais e pedaladas linguísticas ou gafes, como argumentos que se reforçam mutuamente para a destituição da presidenta Dilma, pode ser entendida como demasiadamente forçada ou pouco pertinente. Todavia, se tomarmos a atual situação política brasileira em que o atual presidente, dono de uma retórica, que segue fielmente os modelos da língua padrão, se vê envolvido numa série de denúncias de corrupção, sendo interpelado pela Polícia Federal e o Supremo Tribunal Federal a responder pelo encontro e diálogo que teve com o empresário Joesley Batista, vemos que, mesmo assim, o seu pedido de afastamento da presidência não tem respaldo da maioria da população brasileira. 


\section{REFERÊNCIAS}

ARAUJO, C. A. Dilmês: o idioma da mulher sapiens. Rio de Janeiro: Record, 2015.

CONEIN, B. et alli. Materialidades discursivas. Coord. da tradução: Eni Puccinelli Orlandi. Campinas: Editora da UNICAMP, 2016.

LE BART, C.; TEILLET, P. Erreur, lapsus, gaffes, fautes : le discours politique comme genre. In: RINGOOT, R.; ROBERT-DEMONTROND, P. (Éd.). L'analyse de discours. Rennes: Editions Apogée, 2004. p. 53-85.

MAINGUENEAU, D. Frases sem texto. Tradução de Sírio Possenti et alii. São Paulo: Parábola Editorial, 2015.

PAVEAU, M.-A. Linguagem e moral: uma ética das virtudes discursivas. Tradução de Ivone Benedetti. Campinas: Editora da UNICAMP, 2015.

VICTOR GOMES, M. Das gafes às aforizações em política: questões teórico-analíticas. Relatório (Iniciação Científica) - Centro de Educação e Ciências Humanas, Universidade Federal de São Carlos, São Carlos, 2013. FAPESP - Processo 2013/17191-3.

Recebido em: 19/10/2017

Aprovado em: 21/03/2018 